\title{
«ДИАЛОГ КУЛЬТУР» НА УРОКАХ И ВО ВНЕУРОЧНОЕ ВРЕМЯ КАК СРЕДСТВО РАЗВИТИЯ ЛИЧНОСТНОЙ КОМПЕТЕНТНОСТИ УЧАЩИХСЯ
}

\author{
Самец Наталья Николаевна \\ Государственное учреждение образования \\ "Средняя школа № 139 г. Минска"
}

Цель: повышение профессионального мастерства педагогов-участников мастер-класса в процессе активного педагогического общения по освоению опыта работы по применению технологии «Диалог культур» на уроках русского языка и литературы.

Основные задачи мастер-класса:

- создать условия для профессионального общения, самореализации и стимулирования роста творческого потенциала педагогов;

- повысить профессиональное мастерство участников;

- обозначить актуальность применения технологии «Диалог культур» уроках русского языка и литературы;

- распространить передовой педагогический опыт применения технологии «Диалог культур» на уроках русского языка и литературы;

- провести практическую часть по применению технологии «Диалог культур» уроках русского языка и литературы;

- провести рефлексию продуктивности мастер-класса.

Ожидаемые результаты: использование коллегами в своей педагогической деятельности опыта работы по применению технологии «Диалог культур» на уроках русского языка и литературы.

Оборудование: авторская презентация, ноутбук, мультимедиа проектор, экран для показа презентации, школьный колокольчик (для звонка), ватман (количество листов зависит от количества групп), цветные карандаши, фломастеры.

\section{Ход мастер-класса}

Здравствуйте, уважаемые коллеги! Начать свой мастер-класс хотелось бы словами известного журналиста Александра Боровика: Люблю людей. Чаще всего они говорят: «Я не мог ошибиться!..». И больше всего любят усльишать: «...Tbl сделал невозможное!» Остаётся склеить эти две реплики в диалог. 
Культурологический аспект занимает центральное место как в Концепциях учебных предметов «Русский язык» и «Русская литература», так и в Образовательных стандартах по данным предметам. Как же сделать так, чтобы культурное наследие стала не дополнением к уроку, а было доминирующим не только в воспитании, но в обучении?

Технология «Диалог культур» заинтересовала еще в 90-е годы, когда преподавала несколько предметов: русский, белорусский язык и литературу, мировую художественную культуру. В то время и была определена стратегическая задача: как сделать уроки и внеклассные мероприятия такими наполненными и интересными, что все учащиеся будут воспринимать и воспитание, и обучение как самое необходимое в их жизни, как творческий процесс, требующий постоянного поиска, умения поспевать за жизнью. Внутренний мир современных молодых людей психологически необычайно сложен, подвижен, изменчив, поэтому требуется активная и своевременная помощь со стороны учителя. Но необходимо помнить главное - помощь должна с интересом и благодарностью воспринята, а это бывает довольно трудным делом. С этими трудностями и помогают успешно справляться уроки диалоги культур, так как включают в себя такие процессы, как самопознание и самовоспитание.

Давно известно, что в своем самопознании и самовоспитании ребенок проходит несколько этапов - со дня его прихода в этот мир через взаимодействие с окружающей средой и с другими людьми. С ним происходит процесс намеренного изменения, возведения человеком самого себя на более высокую ступень физического, духовно-нравственного, социального и творческого развития.

Урок диалог культур строится на осознании того, что вся история человечества - это диалог, пронизывающий всю нашу жизнь. Он является по своей действительности средством осуществления коммуникационных связей, условием взаимопонимания людей. Взаимодействие культур - наиболее благоприятная основа для развития межличностных отношений, где активно взаимодействуют равноправные субъекты с учётом их самобытности и своеобразия. Взаимодействие различных культур и цивилизаций на уроках и во внеурочное время предполагает приобретение общих культурных ценностей и даёт возможность самосовершенствования.

Мы, педагоги, должны понимать, что культура - это не просто совокупность материальных предметов, объектов, идей, образов, созданных человеком на протяжении его истории, а ещё и средство солидарности между 
людьми. Но здесь возникает одна проблема: не все хотят принимать чужую культуру, поэтому и возникают конфликты между людьми. Как же этого избежать?

Потому-то и была выбрана такая сфера педагогической деятельности, как диалог культур. Считается, что для того, чтобы возникло понимание между людьми, каждый человек должен развить в себе способность увидеть и услышать другого, признать его право на существование, потому что понятие «культура» предполагает умение вслушиваться, вглядываться, вчитываться. Если с этим не рождаются - значит, этому надо учиться. Девизом деятельности учащихся на уроках диалогах культур стали слова Влада Макеева: «Перестань сравнивать себя с другими. То, что происходит в жизни других - не имеет никакого отношения к тебе. Твоя иель - быть лучше себя вчерашнего. Если ты превзошел себя, ты справился. Концентрируйся на себе - и все получится».

В основу технологии положены идеи М. М. Бахтина о культуре как диалоге, внутренней речи Л. С. Выготского, положения философской логики культуры В. С. Библера.

Обучение с применением технологии по «Диалог культур» предусматривает следующие аспекты:

- общение субъектов диалога;

- сотворчество преподавателя и обучающихся, присвоение ими определенных позиций, типов мышления;

- спиралевидный характер урока-диалога;

- непредсказуемость урока-диалога;

- многоплановость урока-диалога;

- внедрение игровых методик;

- использование других инновационных технологий.

Исходя из этого, на уроке-диалоге культур не только раскрывается внутренний мир ребенка совершенно с другой стороны, иногда неожиданной для него, но и способствует совершенствованию его как неординарной личности.

Перед вами лежат конверты, выньте их содержимое и разложите картинкой вверх. Представьте себе, что вы ученики и вам нужно определить цель урока диалога культур. Непросто, потому что, как уже было сказано, диалог культур, это синтез не только технологий, но и форм, методов и приемов обучения.

Первый прием, с которым мы (учитель-ученик) работаем на уроках, это кроссенс как прием логического и творческого мышления. 
Никто не будет спорить с тем, что каждый учитель должен развивать логическое мышление учащихся. Это является главным требованием и Стандартов, и Концепций по учебным предметам, об этом же говорится и в методической литературе.

Л. Н. Толстой сказал удивительные слова: «Если ребёнок не научился сам ничего творить, то в жизни он всегда будет только подражать, копировать...»

Что же такое кроссенс? Слово «кроссенс» придумано авторами по аналогии со словом «кроссворд», которое с английского означает «пересечение смыслов».

Кроссенс представляет собой ассоциативную цепочку, замкнутую в стандартное поле из девяти квадратиков. Девять изображений расставлены в нём таким образом, что каждая картинка имеет связь с предыдущей и последующей, а центральная объединяет по смыслу сразу несколько. Связи могут быть как поверхностными, так и глубинными, но в любом случае это отличное упражнение для развития логического и творческого мышления.

Читать кроссенс нужно сверху вниз и слева направо (как правило чтения в русском языке), далее двигаться только вперед и заканчивать на центральном 5 квадрате, таким образом, получается цепочка, завернутая «улиткой». Начать можно как первой, так и с любой узнаваемой картинки. Центральным является квадрат с номером 5, он может быть связан по смыслу со всеми изображениями в кроссенсе.

При создании кроссенса можно воспользоваться следующим алгоритмом: 1. Определяем тематику (общую идею). 2. Выбираем 9 элементов (образов), имеющих отношение к теме. 3. Находим связь между элементами. 4. Определяем последовательность элементов по типу связи «крест» и «основа». 5. Сконцентрируем смысл в центральном элементе. 6. Подбираем картинки, иллюстрирующие выбранные элементы (образы). 7. Заменяем выбранные элементы (образы) картинками. Так как основной смысл кроссенса - это некая загадка, ребус, головоломка, то он прекрасно выступает как форма нетрадиционной проверки знаний по предмету.

Применение кроссенса на уроке разнообразно, так как его можно использовать при:

- проверке домашнего задания (с помощью кроссенса рассказать о материале прошлого урока);

- формулировке темы и цели урока (найдите связь между изображениями и определите тему урока; определите, что мы будем изучать); 
- раскрытии информационного блока темы, поиск проблемы (виды, причины, черты, последствия чего-либо в образах и символах);

- закреплении и обобщении изученного материала (кроссенс состоит из изображений, которые появлялись в ходе урока на разных этапах, учащиеся по ним обобщают материал и делают выводы);

- определении творческого домашнего задания (составление кроссенса в печатном или электронном виде на заданную тему, на произвольную тему).

- Вам предлагается составить кроссенс (Приложение 1) и разгадать его смысл (цель урока диалога), используя части целого, которые лежали у вас в конвертах. После того, как вы сложите все квадраты, ваша задача - объяснить кроссенс (определить, о чем идет речь, составить рассказ - ассоциативную цепочку, посредством взаимосвязи изображений). На выполнение я даю 2 минутки (Звучит вальс Е. Доги из кинофильма «Мой ласковый и нежный зверь»).

- Вы поняли, о чем идет речь? Что мы можем рассказать о цели урока диалога культур, используя кроссенс? (Ответы) Да, целью урока диалога является самосозидание личности в пространстве родной и мировой культуры.

Спасибо большое! Было трудно? Да приходится потрудиться, но это оправдывает себя заинтересованностью детей, их желанием отвечать и самостоятельно выполнять кроссенсы.

Основной смысл создания кроссенса - это загадка, головоломка, ребус, задание, которое предназначено для определённой аудитории. Именно в этом качестве оно интересно нам, педагогам. Нельзя отрицать, что наряду с логическим мышлением, развивается зрительная память и связная речь.

На уроках диалогах культур используется ещё и метод ситуационноролевых игр. Давайте представим урок литературы в 6 классе по басне И.А. Крылова «Волк и ягненок». Вам предлагается разыграть сценку «Диалог волка и ягненка» со слов «Как смеешь ты, наглец, нечистым рылом...»

Участники мастер-класса разделены на группы. Задача каждой предположить (после слов автора и реплики волка), как ответит ягненок (пишут свое стихотворное продолжение). Варианты: просто оправдается, предпримет какие-либо меры для своего спасения. Они далее предполагают, как данная ситуация применима к обычной жизни, какие выходы можно найти в такой сложной жизненной ситуации. Далее они создают смысловую схему поведения участников басни, пишут маленькую миниатюру «Как бы я поступил, если меня несправедливо обидели?» 
В современной педагогической практике культурологический подход к урокам литературы предполагает несколько типов интегративных связей:

- последовательный тип интеграции, где материал, принадлежащий к разным видам искусств, объединён в блоки;

- параллельная связь литературы и других видов искусств, когда изучение происходит синхронно на каждом из этапов урока;

- урок со смешанным типом интеграционных связей определяется тем, что может включать разные виды интегративной связи;

- опоясывающий тип интеграционных связей.

На таком уроке при изучении конкретного произведения или темы привлекаются сведения из самых разнообразных учебных предметов и искусств, которые дополняют, уточняют, развивают материал, преломляют его в новых идеях, образах, понятиях, картинах.

Структура занятия напоминает собой «ромашку», в центре которой текст, a ее «лепестки» - материал взятых предметов, объединенный на уровне содержания, методов способов и форм деятельности.

Диалог культур помогает решать многие образовательные задачи, так как воспитывает личность, обладающую ценностными качествами, которой свойственна сила характера, стремление к истине, умение отличать добро от зла, честность мыслей и поступков, искренность, верность своему слову.

\section{Структурные составляющие урока диалога культур}

\section{I. Вступительный этап.}

1. Определение проблемы через слово-текст-образ-мысль

2. Эмоциональная настроенность на решение проблемы.

3. Определение правил взаимодействия.

4. Организация пространства общения.

5. Определение темы и целей урока.

Девиз этапа: «Я мыслю, значит, я существую».

\section{II. Творческо-аналитический этап}

1. Коллективный анализ изучаемого материала через построение схемопор, планов, проектов, презентаций (опережающее домашнее задание).

2. Обретение опыта сотрудничества, состязания, созидания.

Полемические исследования, основанные на тексте. Отбор текстов, передающих ценностные смыслы различных эпох - важное условие достижения образовательных целей. К текстам обязательно формулируются проблемные вопросы, творческие задания.

Девиз этапа: «Я смогу, я сумею, я научусь». 


\section{III.Личностно-рефлексивный этап}

1. Применение полученных знаний на практике через соотнесение, соизмерение, сопоставление, сомнение и др.

2. Собственное самосовершенствование через письменный или устный анализ своих действий и действий участников группы.

3. Комфортное сотрудничество учителя и ученика, помощь другим участникам группы, кому она необходима.

Формы:

а) микродискуссия;

б) устный «поединок;

в) формулировка собственных суждений;

г) тренинги и др.

Девиз этапа: «Сделал сам - помоги другому».

\section{ІУ.Рефлексивно-оценочный этап}

1. Представление своей работы в форме:

а) индивидуального или коллективного проекта (приложение);

б) творческого отчёта (приложение);

в) авторского текста (приложение);

г) схем и рисунков (приложение).

Девиз этапа: «Я не хуже других, но я и не лучше других».

\section{У.Рефлексивный этап}

Определение смысловой составляющей урока

Я понял, что...

Я научился...

Мне еще необходимо повторить...

Девиз этапа: «Я смогу лучше».

На уроке диалоге культур у учителя нет решения на поставленную проблему, он её ищет вместе с учащимися через культурное наследие общества. В этом и заключается существенная разница между проблемным обучением и уроком диалогом культур.

Звучит музыка Антонио Вивальди «Осень»

Дорогие друзья! Представьте, что вы на уроке по написанию сочинения. Вы еще не знаете, какой будет тема урока. Предположите тему урока. Нарисуйте сначала словами, что вы «увидели» в музыкальном фрагменте.

Посмотрите, пожалуйста, на экран. На экране коллажи с изображением осени. 
Это и есть начало урока диалога культур по написанию сочиненияописания природы. Далее идут тексты различных авторов на тему «Осень». С участниками мастер-класса обсуждается каждый текст. Затем им предлагается выписать из данных текстов красивые фразы. Потом подобрать эпитеты к словам (небо, земля, лес, листья, поле, цветы, облака, воздух, солнце). Составляются черновики сочинения (звучит музыка Вивальди), зачитываются варианты созданных работ.

Давайте поразмыслим над вопросом: какие же цели помогает реализовать на уроке технология “Диалог культур”?

Это такие, как:

- формирование умения постигать через смыслы системы ценностей;

- развитие способности проведения мысленного эксперимента, умения работать с текстом, картиной, музыкальным произведением;

- расширение эмоционально-нравственного поля личности;

- создание атмосферы духовности;

- формирование диалогического сознания и мышления;

- обновление предметного содержания;

- соединение в нем различных, не сводимых друг к другу культур.

Диалог разворачивается вокруг основных точек зрения, так как обучение строится не только на сквозном диалоге, но и учитывается внутренний диалог каждого участника, завязанный вокруг основных точек удивления. Таким образом, обучение строится не на основе известных фактов, а на базе реальных текстов и объектов культуры. Уроки помогают искать волнующие всех участников вопросы и решать проблемы, благодаря которым может сформироваться собственный смысл изучаемого материала. Также имеется возможность перерабатывать учебный материал в систему проблемно-коллективных вопросов и задач, что предполагает возвышение их до общечеловеческих проблем через написание научно-практических работ и успешное участие в олимпиадах. Еще создаются условия для проектирования способов взаимодействия участников диалога, их возможных ролей и условий их принятия учащимися и учителем. Выявляются зоны импровизации, при которых трудно заранее предусмотреть поведение его участников. Все участники диалога не решают проблему, а углубляют ее и выводят на вечные проблемы бытия. На таком уроке учитель - друг учащихся и координатор их деятельности: ставя проблему, учитель выслушивает все варианты, помогает проявить различные формы логики 
различных культур, проявить свою точку зрения. Ученик же в диалоге оказывается в промежутке культур, что требует способности удерживать собственное видение мира от осмысления своего «я» до поступка.

Желание участников разобраться со смысловым пониманием текстов рождает вопросы, которые они сами себе выстраивают, помимо вопросов учителя.Успех диалога зависит от того, насколько точно поставленный вопрос выводит в ту область поиска, где может быть найден ответ. Внешне это выглядит как постановка и разрешение проблемы. Участники: ищут, рассуждают, выстраивают логическую цепочку с оглядкой на текст и реалии эпохи. Ведут диалог с другим (автором) текста; диалог со своим «я»; диалог с другими участниками. Идет погружение в сплошной поток культуры, основные ценности которой постигаются через смыслы текста по условнографической схеме урока диалога культур. Схема включает работу над текстом, создание образа, конкретизацию обстоятельств, указания поступка, определение ценности, и, наконец, уяснение ее смысла непосредственно в ходе диалога.

Проведение уроков по технологии «Диалог культур» давало неплохие результаты: все мои ученики стали успешными личностями, а 15 любимых девочек и мальчиков стали учителями русского и белорусского языка и литературы. Не так часто получала награды за свой труд, потому что главным смыслом своей работы считала отношение моих учеников к самому важному в школе человеку - учителю. Каждый год, без исключения, пока работала, получала одну и ту же награду «Моя вторая мама». В гимназии №7 г. Минска получила грамоту «Обыкновенное чудо». На конкурсе «Учитель года-98» заняла 2 место (первое место за проведение урока (100 из 100), проиграла 1 балл в музыкальном конкурсе, но получила приз зрительских симпатий «Талантливый и креативный учитель», что было для меня важнее всех премий и наград).

На экране изображение звездного неба. Звучит стихотворение В.В.Маяковского «Послушайте!» в исполнении автора.

Мы с вами каждый день отрываем новые звездочки - талантливых и способных учеников. Нет не талантливых детей, важно просто сделать так, чтобы они раскрывались на каждом уроке, как лепестки цветов по утрам Нет профессии лучше, чем профессия учителя. Тепло нашего сердца, нашей души обязательно растопит лед недоверия и неприятия учителя как такового, поможет ребятам понять, насколько они талантливы и неповторимы сами как личности. Каждый ребенок на уроке должен чувствовать себя самым умным, 
самым необходимым в образовательном процессе. Василий Осипович Ключевский сказал: «Учителя должны знать, кого им нужно воспитать или научить, знать не только тот педагогический материал, который сидит или бегает под их руководством, но и видеть тот умственный и нравственный идеал, к которому они обязаны приближать эти вверенные им маленькие живые будущности».

И он абсолютно прав, потому что наша основная задача как педагоговбыть вместе с учениками, быть всегда им поддержкой и опорой. А самим быть такой личностью, с которой они будут брать пример.

Рефлексия «Пословиць и поговорки»

Уважаемые коллеги! Выберите, пожалуйста, 2-3 пословицы, которые бы охарактеризовали вашу работу в группах.

- Воля и труд - дивные всходы дают.

- Друг друга поддерживать - победу одерживать.

- Первый блин всегда комом.

- Победа в воздухе не вьется, а руками в труде достается.

- Двое пашут, а семеро - руками машут.

- Труд любит старание.

- Сегодня мы все прекрасно потрудились. Предлагаю каждому участнику обозначить свои впечатления о нашей встрече. Выберите звездочку нужного вам цвета и украсьте наше Звездное небо:

- Красного цвета - понравилось всё.

- Синего - хочу узнать больше.

- Зеленого - заинтересовало, буду применять в своей работе.

- Желтого - я еще не готов применить данную технологию. 
Приложение 1

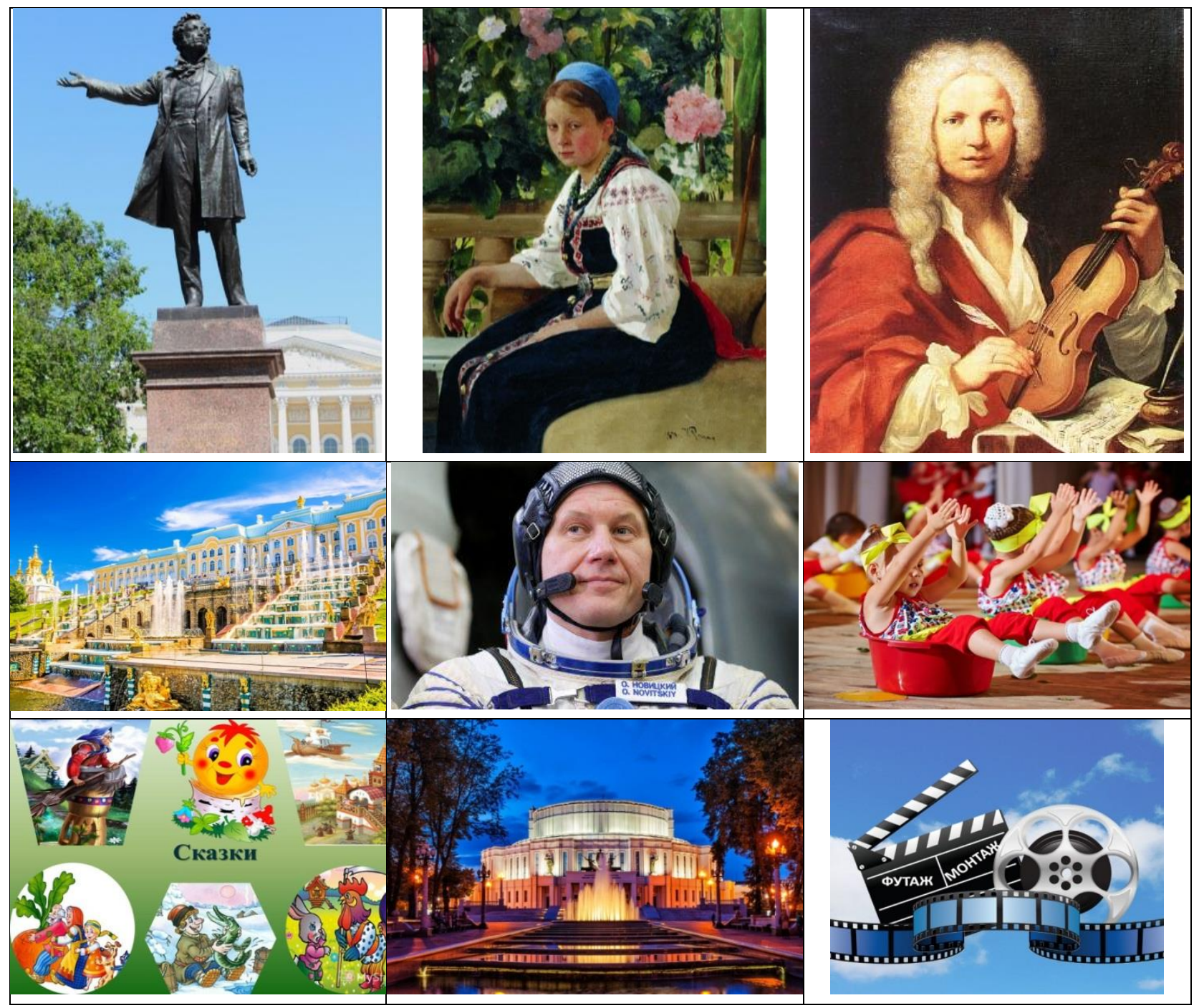

